\title{
Towards a definition of a real-time forecasting network for rainfall induced shallow landslides
}

\author{
S. Segoni ${ }^{1}$, L. Leoni ${ }^{1}$, A. I. Benedetti ${ }^{1}$, F. Catani ${ }^{1}$, G. Righini ${ }^{1}$, G. Falorni ${ }^{1}$, S. Gabellani ${ }^{2}$, R. Rudari ${ }^{2}$, F. Silvestro ${ }^{2}$, \\ and N. Rebora ${ }^{2}$ \\ ${ }^{1}$ Dipartimento di Scienze della Terra, Università degli Studi di Firenze, Firenze, Italy \\ ${ }^{2}$ CIMA Research Foundation - Centro Internazionale di ricerca in Monitoraggio Ambientale, Genova, Italy
}

Received: 6 August 2009 - Accepted: 26 October 2009 - Published: 15 December 2009

\begin{abstract}
PREVIEW is an European Commission FP6 Integrated Project with the aim of developing, at an European level, innovative geo-information services for atmospheric, geophysical and man-made risks. Within this framework, the Landslides Platform Service 2 (forecasting of shallow rapid slope movements) has developed an integrated procedure for the forecasting and warning of distributed shallow landsliding to be used for civil protection purposes.

The Service consists of an automated end-to-end forecasting chain which uses data from a probabilistic downscaled short-term rainfall forecast, soil saturation estimates and meteorological radar outputs. The above data are entered into a hydro-geological model that makes use of an infinite slope approach to calculate the distributed Factor of Safety over the entire basin. All outputs, and much of the input data, are shown on a WebGIS system so that end-users can interactively access and download data. A distinctive feature of the service is the use of an innovative soil depth model for predicting the distributed thickness of the regolith cover within the basin, which is one of the most important parameters controlling shallow landslide triggering.

The service was developed in a pilot test site in NE Italy, the Armea basin. Validation makes use of two rainfall events: one that occurred in 2000 and a smaller, more recent event (2006) that caused fewer landslides. Rainfall data have been used to compute a distributed factor-of-safety map that has been overlaid onto the landslide inventory. Instead of a traditional validation approach based on the number count of correctly identified landslides, we carried out an alternative procedure based on the landslides area that gave outcomes which, for this preliminary stage of the research, can be considered promising.
\end{abstract}

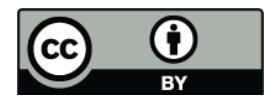

Correspondence to: S. Segoni (samuele.segoni@unifi.it)

\section{Introduction}

The research described here is partially the result of the work carried out within the PREVIEW (PREVention, Information and Early Warning, pre-operational services to support the management of risks) project, an initiative funded within the EU Sixth Framework Programme (FP6) with the aim of developing innovative geo-information prototype services for atmospheric, geophysical and man-made risks to be applied at a European scale. The Landslides Platform is part of the Geophysical Cluster and comprises of two prototype services: monitoring of deep-seated, slow-moving landslides (Service 1) and forecasting of shallow rapid slope movements (Service 2). This work focuses on the results achieved within the development of Service 2.

The main objective of the service was to develop an integrated procedure for the forecasting and warning of distributed shallow landsliding to be used for civil protection purposes. The service combines advanced techniques and tools from different fields including meteorology, hydrology, geomorphological and geotechnical modelling, remote sensing and GIS.

Advanced meteorological forecasting techniques were employed to overcome the limits of traditional approaches. Traditional warning systems, based only on rainfall observations, do not leave enough time to adopt appropriate protection measures against fast phenomena. This concept has been elaborated by different authors (Siccardi, 1996; Ferraris et al., 2002; Siccardi et al., 2005; Bartholmes and Todini, 2005) with reference to flash floods and holds even more strongly when rainfall induced shallow landslides are concerned. Therefore, the challenge is to develop tools able to anticipate what meteorological and hydrological conditions may trigger these landslides before the precipitation event arrives. To succeed, two major sources of uncertainty have to be addressed: the uncertainty associated with

Published by Copernicus Publications on behalf of the European Geosciences Union. 
the meteorological forecast and the uncertainty at the interface between meteorology and hydrology (Castelli, 1995; Droegemeier et al., 2000; Hostetler, 2005).

The uncertainty related to meteorological forecasting of precipitation (meteorological uncertainty) can be dealt with by using meteorological ensemble forecasts. With this approach, for each forecasted event, an ensemble of possible scenarios of precipitation is produced as an input for the hydrological modelling (see e.g. Siccardi et al., 2005). The probabilistic forecasts are based on the assumption that the initial conditions of the model and the physical parameterisations are affected by an intrinsic error which increases with the lead time of the forecast.

The hydrological modelling determines how rainfall interacts with soil, changing its physical properties. This interaction is fundamental to model where and when landslides will occur. In this context, hydrological uncertainty is considered negligible when compared to meteorological uncertainty with reference to the time and space scales of concern in this work.

Another relevant source of uncertainty is the exact definition of the spatial organisation at basin scale of soil properties such as geotechnical parameters and soil thickness. In this paper, this uncertainty will be reduced using a geomorphological based model to consider soil thickness as a random space variable and differentiating geotechnical parameters for each geological unit encountered in the study area.

In this work, the term shallow landslide or soil slip refers to a slope movement in a soil mantled landscape of generally limited size that involves a 1-2 m thickness of soil and is characterized by a rapid onset and runout. According to the classification of Cruden and Varnes (1996), most of these events would appropriately be described as "complex, very rapid, wet, earth slides, debris flows". This designation also takes into consideration the fact that, after the initial movement, the soil structure often collapses and the slide transforms into a debris flow as material is entrained along the flow path. The absence of precursory warning signs, the uncertainty in accurately predicting where the slide will occur, the rapid runout and the capability to increase in volume all make these phenomena very hazardous from a civil protection standpoint.

Many studies have shown that most shallow landslides are triggered by the infiltration of water into a slope (Campbell, 1974; Caine, 1980; Johnson and Sitar, 1990; Wieczorek, 1996; Iverson, 2000). However, this knowledge has not yet led to a reliable forecasting of temporal occurrence, i.e. when the landslide will be triggered. For this reason, many approaches focus more on predicting where a landslide will take place rather than on the timing. Susceptibility maps, for example, generally consider quasi-static parameters such as slope gradient and curvature, soil thickness and permeability to provide an empirical indication of the tendency of slopes to landsliding (Soeters and van Westen, 1996; Aleotti and Chowdhury, 1999; Guzzetti et al., 1999;
Catani et al., 2005). This type of approach, however, is not very helpful in alerting civil protection authorities or other stakeholders to when a potential damaging event could occur. The use of rainfall triggering thresholds to determine when soil slips are likely to occur, on the other hand, is able to provide a statistically-based temporal indication of landslide occurrence on a threshold-alert basis and a large body of literature exists on the topic (Caine, 1980; Innes, 1983; Cannon and Ellen, 1985; Wieczorek, 1987; Larsen and Simon, 1993; Glade et al., 2000; Gabet et al., 2004; Guzzetti et al., 2008). When the rainfall threshold is exceeded during a storm, an alert can be sent out by authorities to provide warning for potential landslides. The drawback of this method is that the spatial prediction is very coarse; usually these alerts are generically raised for large regions without further indications of where landslides are more likely to occur. This method has the advantage of being relatively simple to implement. However, if both a spatial and a temporal forecasting of shallow landslide occurrence are desirable, the most effective approach is to use deterministic models that couple water infiltration schemes with a one-dimensional slope stability analysis (Montgomery and Dietrich, 1994; Wu and Sidle, 1995; Montgomery et al., 1998; Pack et al., 1998; Borga et al., 1998; Burton and Bathurst, 1998; Baum et al., 2002; Casadei et al., 2003; Crosta and Frattini, 2003; Simoni et al., 2008). If the rainfall characteristics of the triggering event are known, these models become useful tools for modelling where and when shallow landslides are likely to occur at a basin scale. Starting from the first attempts, such numerical physically based models have now evolved towards very accurate computation schemes (see e.g. Iverson 2000; Casadei et al., 2003; Simoni et al., 2008). However, most of them (e.g. TRIGRS, Baum et al., 2002 or GEOtop-FS, Simoni et al., 2008) are only capable of evaluating slope stability after the occurrence of a rainfall event when all the weather data are already available, thus, it cannot be used in real time during the evolution of a rainstorm. Moreover, software of this kind use, as input precipitation datum, a single rainfall intensity value to be uniformly applied to the whole studied area. This approach does not allow the spatial variability of a rainstorm to be taken into account, while the use of distributed rainfall maps, like those derived by radar measurements, can greatly improve the result of a distributed soil stability simulation (Crosta and Frattini, 2003).

One of the next logical steps in the evolution of these models, is the coupling with weather forecasts which will make them valuable tools for predicting possible shallow landslide generating events with a lead time sufficient to provide alerts to authorities and the local population (Keefer et al., 1987; Aleotti, 2004; Schmidt et al., 2008). PREVIEW-Landslides Service 2 follows this approach, providing an experimental operative platform for a real-time forecasting network. This completely automated end-to-end chain is composed of a meteorological model (which, properly downscaled, provides short term high resolution rainfall forecasts), an hydrological 


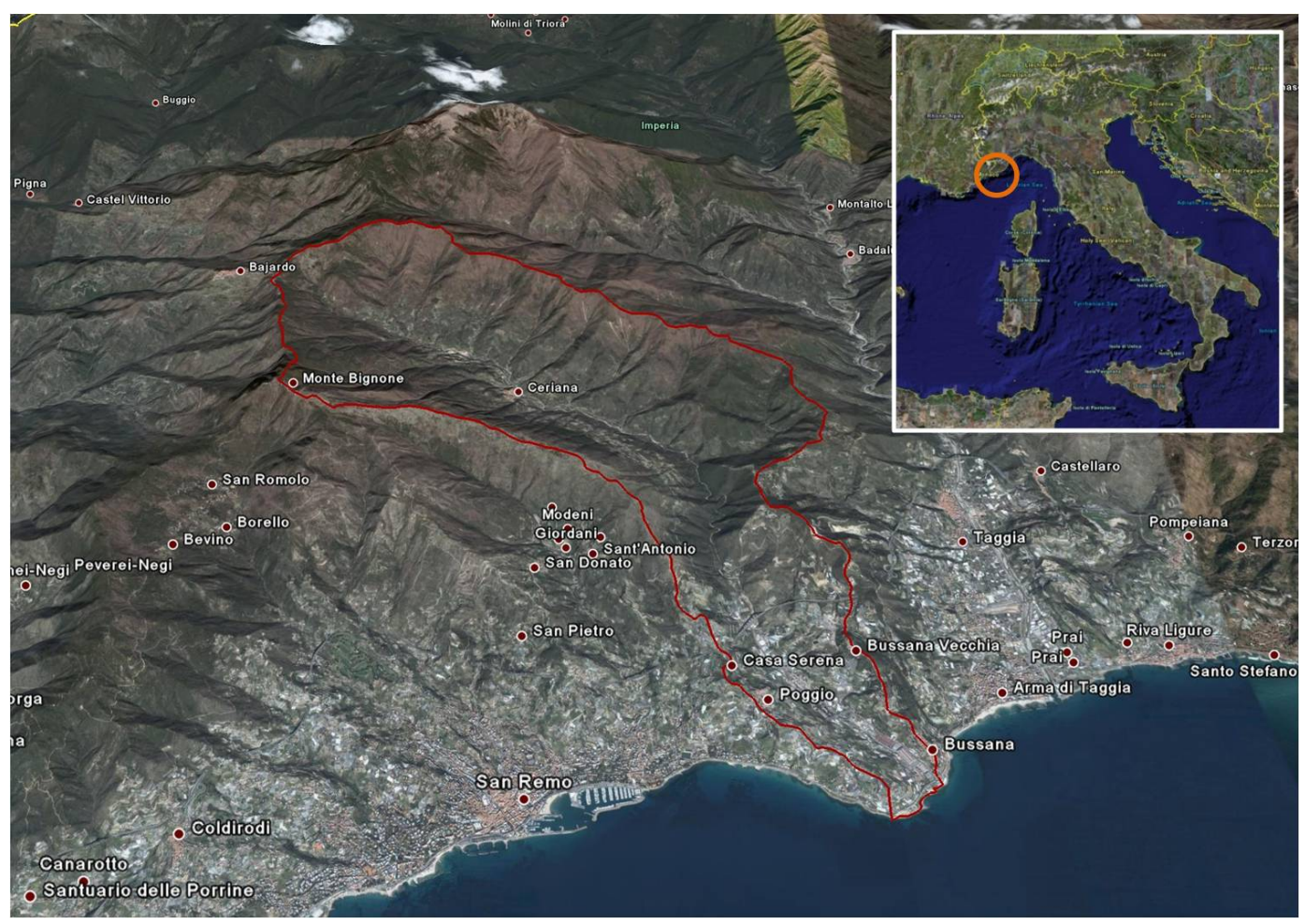

Fig. 1. The Armea valley (outlined in red). The test site is limited to the mountainous mid and high portion of the basin.

model (which, in turn, computes a distributed soil saturation map using radar rainfall maps as input) and a geotechnical model, whose output is a factor-of-safety map to be used for early warning or for civil protection purposes.

\section{Test site}

\subsection{Geographic setting}

The test site is located in Liguria, a region in NW Italy south of the Alps (Fig. 1, top right corner).

Meteorological conditions change at a local and regional scale, due to localized storm cells or to regional cyclonic conditions. The latter is the case when storms move from the Alpine-pre-Alpine sectors to the Tyrrhenian coast. Mean annual precipitation ranges from $750-1250 \mathrm{~mm}$ in the western to $1350-1850 \mathrm{~mm}$ in the central and eastern parts of the region.

Due to the geographical location and to the morphological and geological setting, landslides are frequent in Liguria. According to the Italian archive of historical information on landslides and floods, 1806 landslide events damaged 1233 localities during the period 1800-2001 in the four Provinces of the Liguria Region. The historical information reveals that damaging events are most frequent in the rainy season, during the period September through December, in all four Provinces. Landslides are prevalently represented by soil slips, soil slumps and soil slip-debris flows. These landslides cause economic losses and sometimes casualties. They damage agriculture, settlements, infrastructures and pose threats to the safety of people. Soil slip-debris flows are gravityinduced mass movements and are one of the most hazardous natural phenomena. Their considerable hazard potential is related to the abundance of susceptible areas and the high velocity of the movements. A peculiarity of some failures affecting the area is represented by the presence of old, dry stone walls used to retain soil for agricultural purposes and now completely covered by colluviated material. In general, shallow landslides can be triggered by rainstorms of high intensity and short duration or by prolonged rainfall of moderate intensity.

\subsection{Armea valley}

The studied area corresponds to the middle and high portion of the Armea basin, a $33 \mathrm{~km}^{2}$ wide mountain district characterized by a very high energy of relief, with steep slopes and deeply incised valleys (Fig. 1). Altitudes range from a minimum of $73 \mathrm{~m}$ a.s.l. to a maximum of $1298 \mathrm{~m}$ a.s.l. while slope gradient, extracted from a $5 \mathrm{~m}$ resolution DEM, has a mean value of $26^{\circ}$. From a geological point of view, the area is occupied by Cretaceous Flyschs made up of mainly sandstone and marlstone. Limestones are present as well and a tectonic window lets Eocenic sandstones outcrop in the northern portion of the area. 


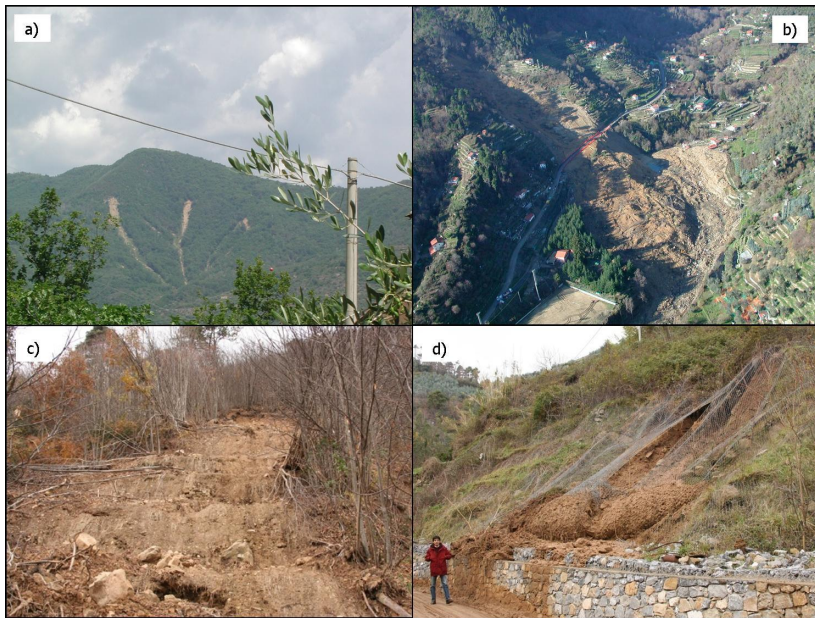

Fig. 2. Debris flows (a) and earth flow (b) from the November 2000 event and two of the superficial landslides triggered on 8 December 2006 in the Armea basin (c) and (d).

The area under investigation has been affected by several rainfall-induced landslide events in the last years. In November 2000, a high-intensity winter storm hit the coast of Liguria. Damage was particularly severe in the Imperia Province where landslides caused three fatalities and severely damaged the infrastructures, some private homes, the agriculture, and the flower industry. Landslides were most abundant at Ventimiglia, near San Remo, and in the Armea and Argentina valleys (Fig. 2). Soil slips were also reported near Mentone, in France. After the event, 1024 rainfall induced landslides were recorded in an area of about $500 \mathrm{~km}^{2}$. Landslides triggered by the high-intensity rainfall were both shallow and deep seated. Shallow landslides were mostly soil slips mobilized into debris flows. In many cases they travelled long distances (up to $1.5 \mathrm{~km}$ in the Armea valley), involving considerable volumes of material.

More recently (8 December 2006), another severe rainfall event struck the Armea valley triggering several rapid, shallow landslides (Fig. 2). This last episode was less destructive than the previous one but, nevertheless, wounded a person and damaged infrastructures, agricultural areas and assets.

\section{Methodology: an end-to-end forecasting chain}

In the PREVIEW-Landslides Service 2 the meteorological, hydro-geological and geomorphological modellings were integrated in an end-to-end chain aimed at forecasting and providing distributed Factor of Safety maps relative to rainfall events with enough lead-time to allow public administrations to undertake safety measures. The various steps, described in the following sections, are logically connected since the output of a modelling is the input of the following one (Fig. 3).

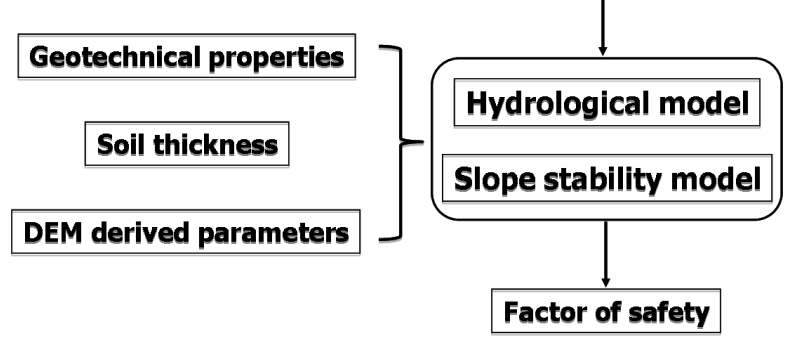

Fig. 3. Architecture of the forecasting chain.

\subsection{High resolution rainfall}

Because of the problems of scales outlined in the introduction, the service needs to represent the rainfall spatial patterns and temporal development with the highest possible detail, both with regard to observed rainfall and forecasted one. In the service, high resolution rainfall fields observed from meteorological ground-based radar and high resolution rainfall forecast by means of a stochastic downscaling procedure are used to feed the hydro-geological models which represents the core of the system.

\subsubsection{Radar rainfall maps}

Observations of intense precipitation events at small spatiotemporal scales are a crucial element both for developing procedures for stochastic downscaling and for providing high-resolution fields to be used to derive soil conditions (e.g. soil moisture).

Meteorological radars are able to reliably detect the spatiotemporal pattern of the observed precipitation field but are not completely satisfactory in estimating the correct precipitation amounts being an indirect measure. On the other hand, rain gauges, due to direct measurements, provide a better estimate of the point precipitation amounts but lack information on precipitation spatial structure and organization.

To overcome such limitation, it is possible to use radarderived rainfall maps that account for the precipitation measured by rain gauge networks. This is done through algorithms that allow for correcting radar-measured precipitation fields by using rain gauge measurements. There is a great number of publications about the theme of radar-rain gauge adjustment, various algorithms have been designed and some operationally implemented (Tonelli et al., 2002; Cuccioli, 2004; Goudenhoofdt et al., 2009; Vincendon et al., 2009); in any cases the use of geostatistic has been introduced to make more sophisticated methodologies and to improve rainfall estimation (Krajewski, 1987; Velasco-Forero et al., 2008, 2009).

In this work, we use an algorithm that combines the uniform range dependent adjustment, by which the bias is removed from radar estimates, and the spatially varying 
adjusting method, by which radar measurements can be adjusted to fit individual gauge observations (Koistinen and Puhakka, 1981; Alberoni and Nanni, 1992). However, the method used is quite simple to implement and it has been used in different contexts, for example at ARPA-SMR, Meteorological Service of Emilia Romagna (Italy) (Alberoni et al., 1992) or in Michelson' (2000); moreover, it does not need great computational resources. The authors consider the proposed algorithm suitable for applications in a real-time operational framework, however, the introduction of different methodologies for radar gauge adjustment could be taken into consideration in future developments.

In the definition, the proposed method consists of an anisotropic adjustment factor for each precipitation structure observed by the radar. This factor is composed of

- a range-dependent component, which depends on the distance between the precipitation structure and the radar,

- a rain-gauge dependent component, that depends on the rain-gauge observations used to constrain the radarmeasured precipitation field.

Multiplication of the adjustment factor field and the original radar field produces the corrected radar field.

\subsubsection{High resolution rainfall forecasts}

Intense rainfall events are one of the main factors that trigger surface landslides. Procedures for issuing early warnings to the population require the knowledge of the precipitation field down to scales of a few square kilometres and tens of minutes. Current operational practice relies heavily on the use of Limited-Area Meteorological Models (LAMs) that, despite the increase in resolution (now up to $10 \mathrm{~km}^{2}$ in some operational configurations), provide reliable precipitation forecasts on scales of about $10^{2}-10^{3} \mathrm{~km}^{2}$ and a few hours (Rebora et al., 2006a). A gap, thus, exists between the scales resolved by limited-area meteorological models and the scales required for properly modelling the landslide process. An option to fill the scale gap and to obtain small-scale rainfall estimates is based on the use of stochastic models for rainfall downscaling.

A stochastic disaggregation algorithm is capable of generating a small-scale fluctuating field from a smoother rainfall distribution on larger scales. In principle, this approach provides precipitation fields that should simultaneously satisfy the large-scale constraints imposed by meteorological forecasts (e.g., the expected average rainfall intensity) and are consistent with the known statistical properties of the smallscale rainfall distribution (Rebora et al., 2006b).

A downscaling model, suitable for operational use in a hydrometeorological forecasting chain, should be simple, robust, computationally fast and linked in a clear way to the large-scale prediction.
In past years, several stochastic models for rainfall downscaling have been proposed (for a review on disaggregation model types, see Ferraris et al., 2003a). All available disaggregation models have been proven to score fairly well in reproducing the small-scale statistical properties observed for precipitation (Ferraris et al., 2003a). However, linking these models with the features of the large-scale fields is not easy. Many downscaling procedures, currently available for operational purposes, account only for the total precipitation predicted by the LAM, while some other models are based on CAPE (Convective Available Potential Energy) predictions (Perica and Foufoula-Georgiou, 1996; Venugopal et al., 1999), while other information provided by the meteorological model are not preserved.

In this project, a downscaling procedure, able to account for the reliable features of the meteorological forecasting, will be used. Its parameters can be directly derived from the large-scale field with no need for calibration.

Ferraris et al. (2003a, b) have shown that the multifractal properties of radar-measured rainfall fields are compatible with those obtained from a nonlinearly transformed autoregressive process. Starting from these results, a new downscaling model has been developed. This procedure is called RainFARM, Rainfall Filtered AutoRegressive Model, and it was proposed by Rebora et al. (2006b) to which we refer for a complete description and further details. The RainFARM belongs to the family of algorithms called metagaussian models (see, e.g. Guillot and Lebel, 1999) and it is based on a nonlinear transformation of a linearly correlated process. The model is able to generate small-scale rainfall fields that take into account not only the total amount of precipitation predicted by the meteorological model but also its (linear) correlation and the position of the large-scale rainfall patterns.

Here the model is used to produce an ensemble of highresolution precipitation forecasts starting from the most recent precipitation prediction produced either by Ensemble Prediction Systems (EPS) or by Limited area Ensemble Precipitation System (LEPS) or deterministic LAM forecasts.

For each forecasted precipitation field, RainFARM provides 100 high-resolution fields on a spatial domain of $448 \mathrm{~km}$ by $448 \mathrm{~km}$ and for the whole temporal extension of the forecast run, at a resolution of $1.75 \mathrm{~km}$ in space and $10 \mathrm{~min}$ in time.

\subsection{Hydro-geological methods}

A further step in forecasting rapid shallow landslides occurrence requires a hydro-geological simulation aimed at depicting how rainfall influences soil moisture over the studied area. This behaviour is derived by a complex nonlinear process that includes a large number of components at different spatial and temporal scales, such as the geological, geomorphological and vegetational characteristics of the hillslopes, the properties of the infiltration process, soil moisture 
re-distribution, the interplay of erosion and deposition, and the spatiotemporal structure of the precipitation fields.

This service provides the soil moisture conditions of a hillslope within a catchment as a basic element of the landslides triggering model.

A minimum set of thematic data is needed in order to build a physically based model for hydro-geological simulations able to reproduce soil moisture conditions of the hillslopes of a basin. These data regard land use, soil properties, topography and spatial data on geology and geomorphology. Therefore, the characterization of the study area, in terms of soil properties and soil thickness, is a crucial step.

\subsubsection{Soil depth}

Although landslides triggering can be often caused by rainfall, many other factors influence slope stability, such as slope morphometry and the physical properties of the soil itself (thickness and mechanical resistance among the most important). The former can be easily derived from an accurate DEM of the area, while the latter requires more attention because of their complex spatial autocorrelation structure.

From this point of view, a distinctive feature of Preview Landslide Service 2 is the use of a spatially variable soil thickness as an input for the landslide forecasting tool. Several studies have shown that soil thickness is one of the most important parameters controlling shallow landslide initiation (Johnson and Sitar, 1990; Wu and Sidle, 1995; Van Asch et al., 1999). Even if there are many methods to estimate soil depth at discrete measurement-points and some able to cope with slope-scale estimates, no effective models have been proposed so far to predict soil thickness over sites as large and as geologically heterogeneous as the Armea catchment. Therefore, at present, when this parameter is needed in basin scale modelling, a constant value (inferred from a few in situ measurements) is often used. This is an extreme simplification, since soil thickness shows a very high spatial variability (Selby, 1993; Birkeland, 1999; Taylor and Eggleton, 2001). Some authors have proposed using spatially distributed soil thickness schemes based on simple correlations between soil depth and morphometric attributes (slope gradient or elevation are the most used) (Saulnier et al., 1997; Salciarini et al., 2006). Such methods, however, despite being easily applicable, are not reliable at the basin scale since the correlation between the used morphological parameter and soil depth is not constant in space and is in turn conditioned by other factors (lithology, vegetation, soil water, climate, human activity, etc.) (Gessler et al., 2000; Saco et al., 2006; Segoni, 2008).

To use the soil thickness as a spatially variable input to the slope stability computation, a recently proposed model called GIST (Geomorphologically Indexed Soil Thickness) was used. GIST is an empirical model that can produce distributed soil thickness maps at catchment scale with a high spatial resolution ( $5 \mathrm{~m}$ in this work); it uses cheap and easily available data and gives a major importance to geomorphological and geological factors (Segoni, 2008; Segoni and Catani, 2008; Catani et al., 2009). The model links soil thickness to gradient, curvature and relative position within the hillslope profile. While the relationship with gradient and curvature reflects the kinematic stability of the regolith cover, allowing greater thicknesses of soil over flat and concave areas (Heimsath et al., 1999; Braun et al., 2001), the distance from the hill crest (or from the valley bottom) should instead account for the position of the considered soil unit within the soil catena (Carson and Kirkby, 1972; Conacher and Dalrymple, 1977; Moore et al., 1993). This last parameter is fundamental: points having equal gradient and curvature can have very different soil thickness due to their different position along the hillslope profile. To be applied, this model requires a few computations to be carried out in a GIS system and a geomorphological survey aimed to recognize the soil catena typical of the hillslopes and to acquire soil thickness measures needed for the model calibration (Segoni, 2008; Catani et al., 2009).

The obtained soil thickness map ( $5 \mathrm{~m}$ resolution) is shown in Fig. 4 and a high dependence on bedrock lithology and on the relative slope position is clearly detectable. In fact, a general tendency of the soil to thicken downvalley is noticeable and sharp discontinuities are met at the boundaries between very different geological units. Both trends match with field observations. In particular, the shallowest soils are met in the calcareous lithotypes (as they usually outcrop at divides and because they undergo a slow pedogenesis), while the highest thickness values are situated in down-valley debris accumulations.

In order to validate the results, the soil thickness was measured at 91 sample points during the field survey. The comparison between the expected (calculated by the GIST model) and observed (measured in the field) soil thickness measures reveals that the overall performance of the model is quite satisfactory: the mean absolute error is $0.28 \mathrm{~m}$, with a $0.27 \mathrm{~m}$ standard deviation. If we consider the accuracy needed in basin scale modelling and the fact that soil thickness in the Armea Creek catchment varies from 0 to $3 \mathrm{~m}$, this accuracy can be considered acceptable. The highest point errors are a small number and in their vicinities or in analogue positions correct estimations are achieved as well. These outcomes suggest that the largest errors are uncorrelated and might be generated by local isolated errors in the estimation of independent variables. For this reason it is quite easy to automatically detect and eliminate such outliers: if we consider the four largest point errors as anomalous data and we remove them from the sample point population, the mean absolute error is reduced to $0.23 \mathrm{~m}$ with a $0.17 \mathrm{~m}$ standard deviation. 


\subsubsection{Initial soil moisture}

The initial soil moisture condition of hillslopes is a crucial factor in determining the activation of soil slips as a consequence of an intense rainfall. Initial soil moisture conditions combine with the real-time rainfall to determine the stability conditions of the soil.

Because of the simplicity of the stability model used in this work, which do not account for the soil moisture evolution especially as far as the medium/long term is concerned, it is necessary to use alternative ways in order to determine and update the initial conditions of the soil at catchment scale.

Given the difficulties associated with estimating the spatial distribution of soil moisture from point measurements on one side and from satellite observations from the other, soil moisture is often estimated from hydrological models (Mancini and Troch, 1995; Bolognani et al., 1996) and this work makes no exception to this tendency.

Published hydrologic models vary in the level of detail they use in representing the physical system and temporal variations of the driving forces. Some of the important differences among the several published hydrologic models are: (i) the computation of evapotranspiration; (ii) the partitioning between infiltration and runoff; (iii) the temporal definition of evapotranspiration demand and precipitation; (iv) the computation of vertical and lateral redistribution; and (v) the number of soil layers used (Schmugge et al., 1980; Singh, 2002).

Two different philosophies affirmed themselves in modelling soil moisture maps at catchment scale. The first one makes use of SVAT (Soil Vegetation Atmosphere Transfer) models (e.g. Arnold et al., 1993, 1995, 1998; Neitsch et al., 2002a, b). This family of models concentrate on the representation of the vertical fluxes and are often implemented in 1-D configuration. The second one refers to fully distributed continuous hydrologic models (e.g., TOPMODEL, Beven et al., 1995). These models include the schematization of horizontal and vertical fluxes, but, often, they do not solve explicitly the energy balance and make use of closure models for the computation of the evapotranspiration term. Both approaches show advantages and drawbacks.

In this work, a continuous distributed hydrological model has been used that tries to merge the two above mentioned approaches: the C-DRiFt model (Gabellani, 2005; Delogu, 2008).

The model solves explicitly both the continuity equation and the energy balance in a distributed scheme, using wellknown simplifications. It uses a modified Horton method to simulate the infiltration process (Gabellani et al., 2008) and considers the soil a porous medium schematized as a reservoir with two parameters: $V_{\max }$ and $f_{0}$ (Gabellani et al., 2005). The first represents the soil-water capacity expressed in millimetres $(\mathrm{mm})$, the latter is the initial infiltration capacity for a dry soil expressed in millimetres per hour $(\mathrm{mm} / \mathrm{h})$. Both parameters are a function of soil type and soil use. For

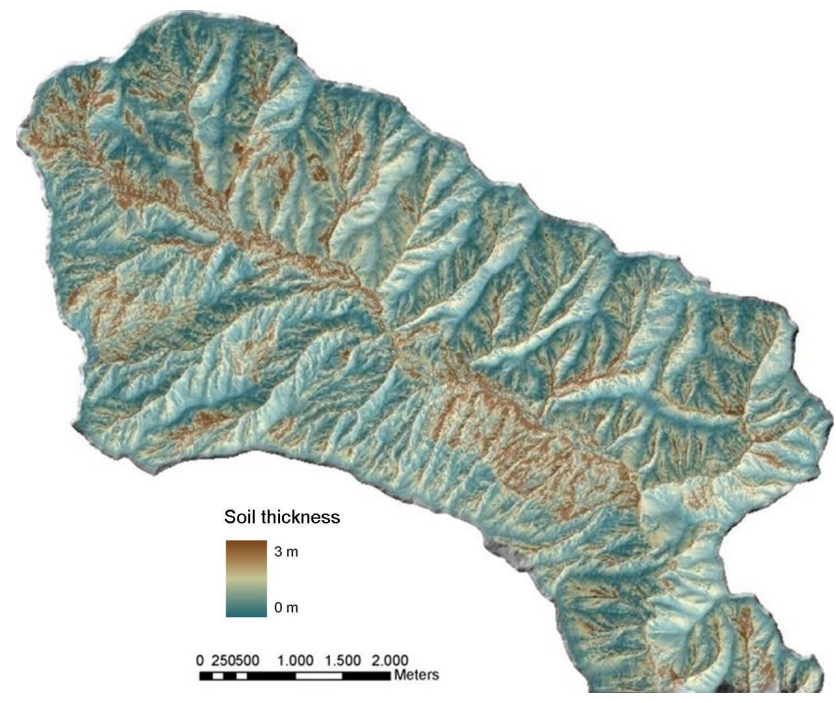

Fig. 4. Soil thickness map obtained by means of the GIST model.

the energy balance the model uses the widely used approximation called "force-restore equation", to explicitly allow for the computation of evaporation and transpiration without the need of empirical closure models (Dickinson, 1988; Ren and Xue, 2004). These schematizations allow the quantification of the partitioning of precipitation water into infiltration and runoff and regulate the hypodermic flow and the recharge of deep water, where vertical and lateral distribution are managed in a distributed model. In this way, a dynamic description of the soil moisture state is possible for each pixel in which the basin is discretized (Giannoni et al., 2000, 2005; Gabellani, 2005 for details).

Results of the simulations are hourly maps of soil moisture content for each pixel within the target area. The soil moisture content is expressed as a degree of saturation defined as $V(t) / V_{\max }$ where $V(t)$ is the actual soil-water content at time $t$ and $V_{\max }$ is the soil retention capacity. This quantity in an essential input for the geological model of soil slips triggering.

\subsubsection{Soil stability model}

The last element of the forecasting chain is the soil stability model, with its aim at computing the Factor of Safety on a pixel by pixel basis over the entire area. For this purpose, a modified version of the infinite slope formula, formerly proposed by Skempton and Delory (1957), has been adopted and applied in a distributed way in the Armea basin:

$\mathrm{FS}=\frac{\left(\frac{c^{\prime}}{\gamma z}\right)+\left(\cos ^{2} \theta-\frac{u}{\gamma z}\right) \tan \phi^{\prime}}{\sin \theta \cos \theta}$

Where:

FS is the Factor of Safety (see Sect. 3.3 for details), $z$ is soil thickness, provided by the GIST model 
(cf. Sect. 3.2.1), $u$ is pore water pressure, obtained with the C-DRiFt model (cf. Sect. 3.2.2),

$\theta$ is local slope gradient, derived from the DEM,

$\gamma$ is soil unit weight,

$\phi^{\prime}$ is soil internal friction angle,

$c^{\prime}$ is soil cohesion.

Each input data is provided in the form of a $5 \times 5 \mathrm{~m}$ cell raster, thus, allowing the calculation of the Factor of Safety (FS) with the same spatial resolution.

To grant geotechnical parameters of the soil $\left(c^{\prime}, \gamma, \phi^{\prime}\right)$ a certain degree of spatial variability, a distinct value was assigned to each geological unit encountered in the area, so that $5 \times 5 \mathrm{~m}$ cell rasters could be set up and used as random space variables in the soil stability model. The geotechnical parameter values were derived from laboratory analyses of samples and from data sets already available at the Earth Science Department of Florence (Leoni, 2009).

The Infinite Slope theory requires that the slip surface be parallel to the topographic surface and that the slip surface depth be approximately constant and small compared to the overall length of the displaced mass. Both circumstances seem to be verified in most part of the shallow rapid landslides occurred in the Armea basin. At this, the infinite slope stability approach, but not very accurate, was chosen mainly because it is simple and easy to apply over large areas in which detail scale continuous measurements of geotechnical parameters are lacking.

\subsection{Factor of Safety map}

The outcome of the soil stability model (and, eventually, of the entire forecasting chain) is a raster map containing the spatial distribution of the Factor of Safety within the Armea basin (Fig. 5). The FS, produced for each pixel of the raster map, is expressed as a pure number that represents the stability of the slope: the higher the FS value the higher the slope stability. In more detail: a value of less than one indicates unstable conditions, implying that at this location the slope should already have failed; values just above one indicate critical conditions that could lead to failure, while greater values indicate more stable slopes. Classification of the distributed FS values will then identify the landslide prone areas and provide a synoptic view of the slope stability within the study site at each computational step.

\subsection{Service description}

The forecasting chain described above has been completely automated so that a new procedure may be launched at $6 \mathrm{~h}$ intervals with updated rainfall information.

The final product is a Factor of Safety map published on a WebGIS platform that is accessible to the end users of the

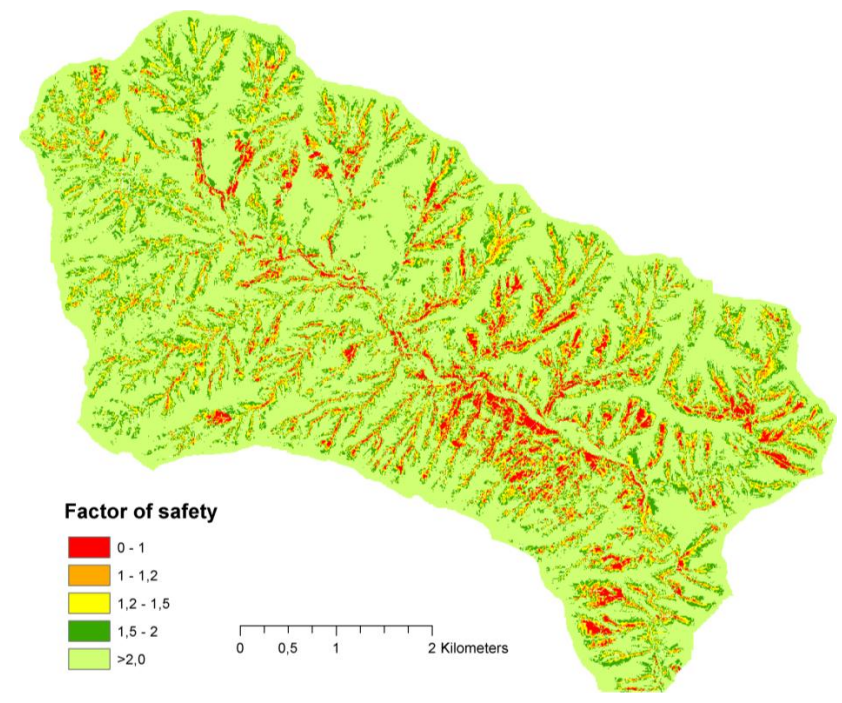

Fig. 5. The Factor of Safety map related to 8 December 2006.

service (public administration offices such as Civil Protection, Province or municipalities).

\subsubsection{Data flow}

The network realized for the development of the Service is composed of three Linux servers: one is located in Savona at the Centro di ricerca Internazionale in Monitoraggio Ambientale (CIMA), one in Florence at the Earth Science Department and one in Rome at Telespazio (a Finmeccanica/Thales company) headquarters. With the use of synchronization tools, data are copied from one server to another as soon as they are created in near real-time (Fig. 6).

The data flow (Fig. 6) starts at CIMA where data from the Monte Settepani radar and the precipitation forecast of the COSMO-LAMI LAM are received and processed to produce soil saturation maps and downscaled weather forecasts for the Armea basin. Using a synchronization tool, the meteorological data are transferred on the server of the Earth Science Department in Firenze where they merge with the local database on geomorphological and geotechnical properties. A shell script checks every five minutes if new data are available and as soon as it finds a new saturation map, a new stability analysis routine is launched. This software, developed at the Earth Science Department, uses as input data the maps of the geomorphological and geotechnical properties and the new saturation map and produces as output an updated map of the Factor of Safety for the Armea basin. Right afterwards, this new map is transferred to Telespazio headquarters' web server where it is published on a WebGIS platform and shared with the end users. An important feature of this data flow is that the whole procedure is completely automatic and efficient with a delay of 10 to $15 \mathrm{~min}$ from the computation of a new saturation map to the publication 
of the new Factor of Safety map on the WebGIS platform. Consequently, the time interval between each launch of the forecasting chain (set to $6 \mathrm{~h}$ at the moment) could be reduced to meet specific needs of the end-users.

\section{Validation}

The processing chain, described above, can be used for selfvalidating predictions using the observed radar rainfall without applying the forecast segment that uses the downscaling procedure. In this way, the modelling chain will be tested for its capacity in identifying the landslide hazard in a hind-cast exercise on two events.

Validation of shallow landslides forecast is not an easy task. It requires the occurrence of several factors: one or more severe rainstorms that trigger landslides, localization of the occurred landslides, detailed temporal and spatial knowledge of the triggering rainfall intensity and duration characteristics, and knowledge of the antecedent soil moisture conditions in the basin.

In the Armea basin, the November 2000 storm satisfied the first two of these requisites, but unfortunately only sketchy information about the rainfall data is available and none regarding antecedent soil moisture conditions. However, on 8 December 2006, a storm occurred in the Armea basin. Although it was significantly smaller than the 2000 event, it nonetheless triggered several superficial landslides and caused a certain amount of damage. Thus, for validation purposes, data related to the 2006 event were used.

As far as the mapping of landslides through remote sensing data is concerned, optical satellite remote sensing technology has recently been exploited and also used for landslide hazard and risk assessment (Metternicht et al., 2005), since it is capable of providing reliable, cost-effective and repetitive information over wide areas. Very high resolution (VHR) satellite imagery (Ikonos, Quickbird, Orbview, Worldview) can provide a powerful tool for a quick reproduction of a map, up to a scale of 1:2000, of local events: thus, they represent a viable tool in many fields including landslides in providing important observations that supplement traditional field reconnaissance (Hervas et al., 2003; Chadwick et al., 2005; Casagli et al., 2005). In fact, one benefit of obtaining satellite imagery is the ability to evaluate the extent of damages even in areas where field surveys are difficult. Furthermore, due to the synoptic view, satellite imagery allows a wide overview of environmental parameters and potential interactions between failures. These observations are difficult to formulate from the ground during traditional survey and can complement field reconnaissance observations.

Following the landslides occurrence of December 2006, a multispectral, pan-sharpened Quickbird satellite imagery was acquired on 13 March 2007, three months after the events, with a mean ground pixel size of $0.70 \mathrm{~m}$; the average sun azimuth and elevation angles at the acquisition time

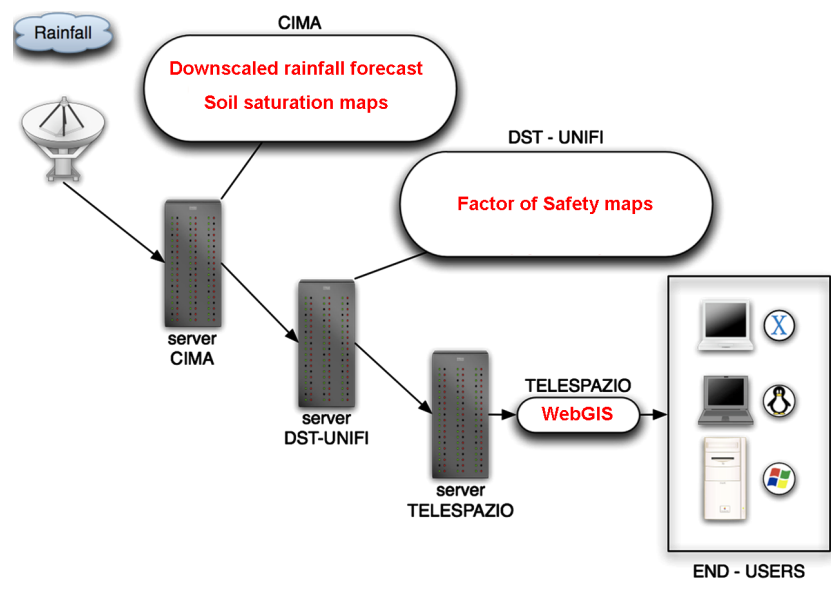

Fig. 6. Data flow.

were $160.82^{\circ}$ and $41.62^{\circ}$, respectively, while the off nadir angle was $14^{\circ}$. The image was orthorectified applying the rational polynomial coefficients (RPC) model to a selection of 70 evenly distributed ground control points (GCP) retrieved from recent topographic maps at 1:5000 scale. The elevations of the points were taken from a digital elevation model (DEM) with a grid resolution of $5 \mathrm{~m}$, produced from the digitized topographic maps with a contour interval of $5 \mathrm{~m}$. Optical data have been processed through radiometric enhancement in order to produce the best false colour composites for visual interpretation. Simple red-green-blue colour composites were used as the most effective way for landforms interpretation (Fig. 7); the image analysis allowed to accurately identify new landslides as small as $2-3 \mathrm{~m}$ in width (Fig. 8), as well as relict landslides. The photointerpretation of the satellite image was performed in a GIS environment using the typical criteria of feature analysis and recognition due to the difference in spectral reflectance, texture and pattern. Main interpretation keys were gathered from the ancillary data, photos and observations collected during the field work.

The final result was a complete post-event landslide inventory map retrieved from the satellite image (Fig. 8). The main step of the validation consists of the direct comparison of the FS map generated by the Service with the new landslide inventory using the data from the 8 December 2006 rainfall event. But if it is clear that a single pixel is to be considered stable (unstable) when its FS value is greater (lower) than unity, uncertainty arises from how to consider a landslide prediction as accurate. How many pixels within the landslide area should have a value near or below unity? Is one unstable pixel enough to destabilize a larger area? Where should the unstable pixels be located within the landslide boundary?

We decided to classify the pixels in three instability classes according to their Factor of Safety value: high instability (FS $\leq 1$ ), moderate instability $1<\mathrm{FS}<1.3$ and stability $\mathrm{FS} \geq 1.3$. The break value between the first two classes directly follows the definition of Factor of Safety 

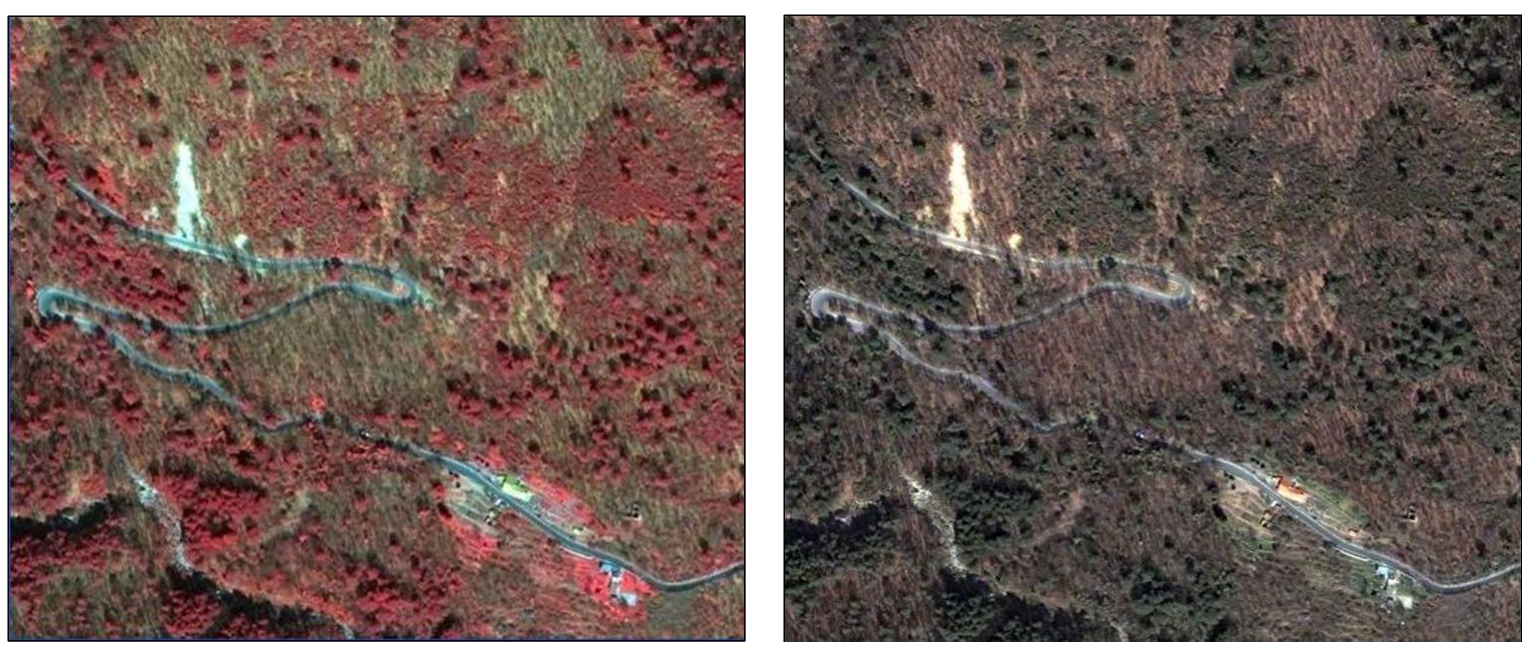

Fig. 7. Detail of the satellite image showing a landslide which is affecting a road. On the left: false colour composite of bands 4 , 3 , and 2 ; on the right: true colour composite (bands 3,2 , and 1).

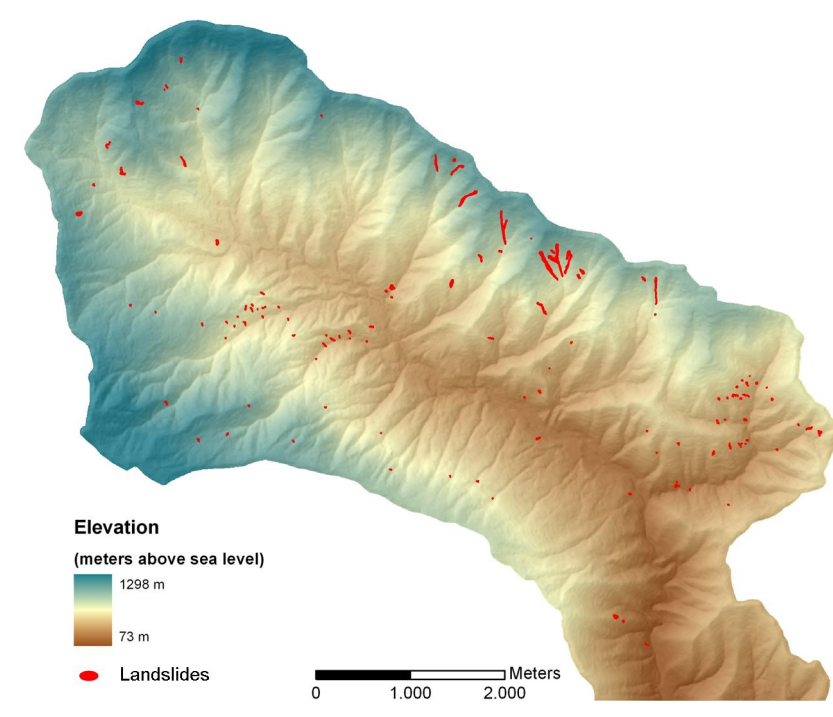

Fig. 8. New landslide inventory map generated from the 8 December 2006 event.

(see Sect. 3.3), while the intermediate class of stability was adopted as a "security measure" to avoid possible misinterpretation of hazardous conditions due to errors in the model or in the parameterization of its physical variables. Subsequently, we decided to classify a landslide area as highly unstable when at least $10 \%$ of the area is composed by pixels with high instability $(\mathrm{FS} \leq 1)$. If the landslide area has at least one tenth of highly or moderately unstable pixels, it is classified as moderately unstable, while if the sum of the highly and moderately unstable pixel does not reach one tenth of the total amount of pixel composing the landslide area, the latter is classified as stable.
The digital inventory of the 2006 landslides was overlaid on the FS map in a GIS environment and the values of the cells falling within the landslide polygons were extracted and analyzed statistically using the definitions given above. Since landslides reported in this inventory are recent and, however, subsequent to the time of acquisition of the DEM (from which many static data used in the model were derived), even a static inventory of landslides can be used to validate the FS map. The number of correct predictions is rather low: only the $13 \%$ of the 2006 landslides are located in an area classified as highly unstable by the model and the $19 \%$ are classified as moderately unstable. In addition, false-negatives (landslides occurred but not correctly identified) are common (the $68 \%$ of the total number of landslides is situated in areas predicted as stable). False-positives are quite frequent as well: the $4.2 \%$ of the area of the basin that was not affected by landslides during the rainfall event is erroneously classified as highly unstable and the $8.1 \%$ is considered moderately unstable. These results can be considered quite poor, but the high number of errors is explainable as follows:

1. Many landslides did not occurred in 2006 just because they had already happened in 2000, therefore, a high number of false-positive occurs if the sole 2006 event is used for the validation given the fact that all input data (but rainfall) pre-date the November 2000 event. This issue can be worked out by including in the validation the landslides from the 2000 event as well. To stress the fairness of this modus operandi, it has to be reminded that the November 2000 rainfall event was more severe than the one occurred in 2006 and that the topography used in the forecasting chain is older than 2000.

2. Many of the missed landslides (false-negatives) are very small: the histogram in Fig. 9 shows that 71 landslides 


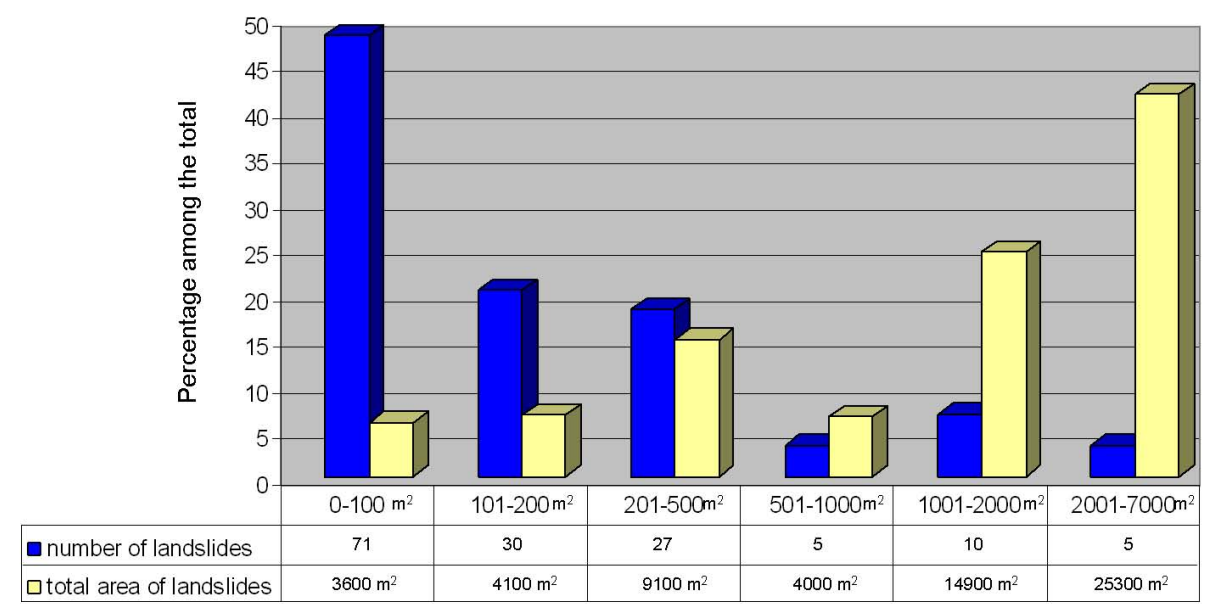

Fig. 9. Landslides composing the 2006 event, grouped into classes according to their extension (x-axis). Large landslides are less abundant than the small ones, but their relevance becomes evident when their extension is taken into account (yellow bars): validation should consider this effect.

occurred in 2006 are less than $100 \mathrm{~m}^{2}$ (49\% of the total number but only $6 \%$ in terms of areal extension). They are mainly represented by tiny soil slips, many of which corresponding to just a single pixel $\left(25 \mathrm{~m}^{2}\right)$. Such events may be considered insignificant from a risk assessment point of view, because a very small risk is associated to them and their validation should be more properly done integrating over sub-basins according to e.g. Strahler ordering (Catani et al., 2008). Therefore, failures of the model in predicting such small events cannot be considered as critical errors. Moreover, this occurrence suggests that a different weight should be given to landslides proportionally to their damaging potential. Since the magnitude of a shallow landslide can be directly correlated with its area, more relevant statistics may be computed by analyzing not the number of missed and correctly identified landslides but their extension, comparing the total areas of the events correctly identified and missed.

Taking into account the above points, the FS map has been validated making use of a landslide inventory composed of both the 2000 and 2006 events and considering the extension of the landslides (with this approach, a landslide of $1000 \mathrm{~m}^{2}$ counts as 1000 , one of $25 \mathrm{~m}^{2}$ counts as 25). By means of this approach, better results were achieved. Landslides correctly identified represent $30 \%$ of the total (135 amongst a population of 446 ) but $54 \%$ in terms of area. This means that the $54 \%$ of the area affected by landslides was correctly identified by our modelling. The $26 \%$ was classified in the moderately unstable class (thus, providing a risk awareness even if at a lower extent) and only the $20 \%$ was erroneously interpreted as stable. The number of false positives is also quite low, since only the $4.0 \%$ and the $4.9 \%$ of the stable area of the Armea basin was erroneously mapped as, respectively, highly and moderately unstable.

\section{Discussion}

The validation of the proposed forecasting network has a fairly strong dependence on the validation procedure. This is due to the fact that both landslide inventories are composed by many small events and fewer large ones. In particular, the 2006 event is represented by 71 (49\% of the total population) tiny slides with a lower than $100 \mathrm{~m}^{2}$ areal extension. The forecasting chain fails to detect most of these very small events in their exact location.

A crucial point of the procedure is the quantification of the influence of different sources of uncertainty on FS maps. The error in the Factor of Safety prediction is the sum of the errors in the input static data (physic and geotechnical properties of the terrain), the errors in acquiring the dynamic data (radar measurement of rainfall intensity) and the errors of each single computational component of the end-to-end chain, e.g. downscaling of rainfall intensity, calculation of the soil moisture (by means of C-DRiFt model) and, finally, computation of the Factor of Safety using the infinite slope formula. At present, a sensitivity analysis has been carried out only on the soil stability model (Leoni et al., 2008) as a stand-alone static module. Figure 10 shows that the static input data (geotechnical and geometrical parameters) weigh in the Factor of Safety value more than soil saturation. But, considering the declared intent of tuning and upgrading the Service, in the long run, those relative weighs could invert: the uncertainty of the static data could be more easily reduced (e.g. by measuring and defining their values once and for all), while the prediction of soil saturation variation in time appears more challenging. Many hydrometeorological studies confirm that meteorological uncertainty has the highest influence on flood forecasting procedures output (e.g. Siccardi et al., 2005; Rebora et al., 2006a; Hardenberg et al., 2007). Since the procedure proposed here shares many elements with a flood-forecasting procedure, we might also assume 


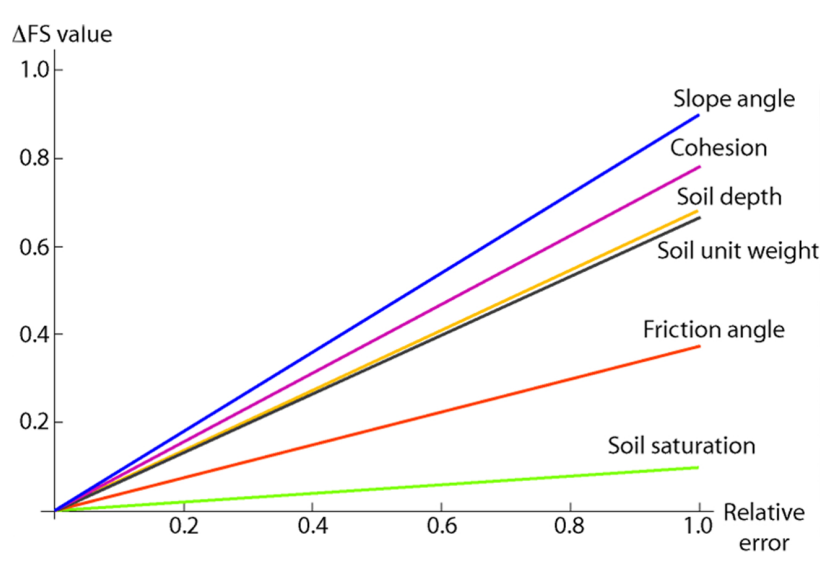

Fig. 10. Graphic showing how much each input parameter of the slope stability module weighs in the Factor of Safety value. The sensitivity analysis was performed by Leoni et al. (2008), using the partial derivative error propagation method.

that the uncertainty Factor of Safety maps is dominated by the uncertainty associated with rainfall forecast. However, the weight of uncertainty derived from different elements of the procedure has to be further investigated. This result can only be achieved by a long-term pre-operational test that allows evaluating the performances of the procedure under different input conditions.

In addition, the infinite slope formula used in the slope stability module is not appropriate to compute the Factor of Safety related to landslides with a low depth/length ratio. This is probably the main reason why the model produces so many errors in recognizing tiny soil slips; their length is comparable with their depth. However, errors of this kind can be considered negligible since such small events pose a very low risk. Instead of removing the small soil slips from the validation process, we decided to adopt another approach: as an alternative to counting how many landslides were correctly or erroneously identified by our forecasting chain, we took into account their areal extension. This is equivalent to assigning each landslide to a different weight directly proportional to its extension. The results achieved with this approach can be considered more reliable and quite satisfactory for this stage of the research. In fact, the main objective of this work was the building-up of the automated forecasting chain and the testing of its capability to be used in landslide risk assessment. The results, that are far from being definite, should be considered preliminary since further advances will be necessary to improve the overall performance of the Platform.

Each element of the automated end-to-end forecasting chain (namely the meteorological, hydrological and geotechnical models) can be replaced with an improved one in order to enhance the final results of the whole network and we have already planned some further refinements. First of all, a more sophisticated slope stability model will be included in the Platform, making use of Iverson's approach to the infinite slope theory (Iverson, 2000) and adding the effect of the apparent cohesion that takes place in unsaturated soils because of suction forces (Mitchell and Soga, 2005; Leoni, 2009). Secondly, the whole forecasting chain will be based on a probabilistic approach, to be used both in the radar rainfall predictions and in the slope stability modelling. Lastly, significant advances in prevention and early warning could be made when outcomes of other PREVIEW services (e.g. flash flood forecasting, Vincendon et al., 2009) will be finally integrated in a single operational procedure involving related risks.

\section{Conclusions}

In the framework of the Preview Service 2, a forecasting chain for the provision of spatial location and temporal occurrence of shallow landslides has been set up. The network is composed of: i) a meteorological module for the forecasting of short-term rainfall data; ii) a hydrological module which models the spatial and temporal distribution of the water content in the terrain; iii) a geotechnical module for the modelling of slope stability.

The forecasting chain can be upgraded at any time, since every model used at each computational step can be substituted with a more effective one without influencing the general functionality of the processing flow. From this point of view, the results presented here should be considered preliminary: in fact, at present, we are working to include in the network a more sophisticated approach for the modelling of slope stability.

Among the static data used in the forecasting chain, a special mention is due to soil thickness, a very important parameter in controlling shallow landslides occurrence. We have used it as a spatial variable to feed-in both the hydrological and the geotechnical models. The spatial distribution of soil thickness was obtained by means of a newly proposed method (Catani et al., 2009; Segoni, 2008) with an acceptable error ( $23 \mathrm{~cm}$ mean absolute error).

The chain has been completely automated in every step, from the acquisition of the dynamic rainfall data to the calculations of the hydrological and geotechnical models and, finally, to the publishing via WebGIS of reliable predictive Factor of Safety maps with enough lead-time to raise alerts when necessary.

The automated network allows shallow landslides forecasting but it can be used manually with any set of data of interest. The latter modality has been used for the validation of the Service, using rainfall data from a severe meteorological event which triggered several shallow landslides in December 2006. Validation showed somewhat contradictory results: only when it was performed taking into account the areal extension of the occurred landslides it provided outcomes that can be considered promising. In fact, this stage of the research consists primarily in the building of a completely automated chain for shallow landslides forecasting; even if the 
Service is not perfectly tuned and not fully validated, due to the limited data available, each of its components reports a practical solution to a specific technical problem involved in the complex process of modelling time and space of occurrence of shallow landslides. At this stage, the various issues were addressed considering simple and easily implementable solutions, but in the near future, we plan to upgrade the service substituting each component with a more advanced one, in order to reduce the errors in shallow landslides risk assessment.

Acknowledgements. This work was performed in the framework of FP6 EC project "PREVention Information and Early Warning" (PREVIEW, contract number 516172). All the people that have contributed to the development of Landslide Service 2 are fully acknowledged.

Edited by: M. Arai

Reviewed by: L. Franzi and another anonymous referee

\section{References}

Alberoni, P. P. and Nanni, S.: Application of an adjustment procedure for weather radar, in: Proceedings of the 2nd International Symposium on Hydrological Applications of Weather Radar, University of Hannover, Germany, 7-11, 1992.

Aleotti, P. and Chowdhury, R.: Landslide hazard assessment: Summary review and new perspectives, B. Eng. Geol. Environ., 58, 21-44, 1999.

Aleotti, P.: A warning system for rainfall-induced shallow failures, Eng. Geol., 73, 247-265, 2004.

Arnold, J. G., Srinivasan, R., Muttiah, R. S., and Williams, J. R.: Large area hydrologic modelling and assessment: Part I. Model development, J. Am. Water Resour. As., 34(1), 73-89, 1998.

Arnold, J. G., Allen, P. M., and Bernhardt, G.: A comprehensive surface-groundwater flow model, J. Hydrol., 142, 47-69, 1993.

Arnold, J. G., Williams, J. R., and Maidment, D. A.: Continuoustime water and sediment routing model for large basins, J. Hydraul. Eng.-ASCE, 121(2), 171-183, 1995.

Bartholmes, J. and Todini, E.: Coupling meteorological and hydrological models for flood forecasting, Hydrol. Earth Syst. Sci., 9, 333-346, 2005, http://www.hydrol-earth-syst-sci.net/9/333/2005/.

Baum, R. L., Savage, W. Z., and Godt, J. W.: Trigrs, a fortran program for transient rainfall infiltration and grid-based regional slope-stability analysis, Open-file Report, US Dept. of the Interior, US Geological Survey, 2002.

Beven, K., Lamb, R., Quinn, P., Romanowicz, R., Freer, J.: TOPMODEL. In Computer Models of Watershed Hydrology, edited by: Singh, V. P., Water Resources Publications, 627-668, 1995.

Birkeland, P. W.: Soils and geomorphology, Oxford University Press, Oxford, 430 pp., 1999.

Bolognani, O., Mancini, M., and Rosso, R.: Soil moisture profiles from multifrequency radar data at basin scale, Meccanica, 31(1), 59-72, 1996.

Borga, M., Dalla Fontana, G., Da Ros, D., and Marchi, L.: Shallow landslide hazard assessment using a physically based model and digital elevation data, Environmen. Geol., 35, 81-88, 1998.

Braun, J., Heimsath, A. M., and Chappel, J.: Sediment transport mechanisms on soil-mantled hillslopes, Geology, 29(2), 683686, 2001.

Burton, A. and Bathurst, J. C.: Physically based modelling of shallow landslide sediment yield at a catchment scale, Environ. Geol., 35, 89-99, 1998.

Caine, N.: The rainfall intensity: duration control of shallow landslides and debris flows, Geogr. Ann. A, 62, 23-27, 1980.

Campbell, R. H.: Debris flows originating from soil slips during rainstorms in southern California, Q. J. Eng. Geol. Hydroge., 7, 339-349, 10.1144/gsl.qjeg.1974.007.04.04, 1974.

Cannon, S. H. and Ellen, S.: Rainfall conditions for abundant debris avalanches in the San Francisco bay region, California, California Geology, 38, 267-272, 1985.

Carson, M. A. and Kirkby, M. J.: Hillslope form and process, Cambridge University Press, Cambridge, 475 pp., 1972.

Casadei, M., Dietrich, W. E., and Miller, N. L.: Testing a model for predicting the timing and location of shallow landslide initiation in soil-mantled landscapes, Earth Surf. Proc. Land., 28, 925-950, 2003.

Casagli, N., Fanti, R., Nocentini, M., and Righini, G.: Assessing the capabilities of VHR satellite data for debris flow mapping in the Machu Picchu area, in: Landslides, Risk analysis and Sustainable Disaster Management, edited by: Sassa, K., Fukuoka, H., Wang, F., and Wang, G., Proceeding of the First General Assembly of the International Consortium on Landslides, 2005.

Castelli, F.: Atmosphere modelling and hydrology prediction uncertainty, Proc. US-Italy Research Workshop on Hydrometeorology: Impacts and Management of Extreme Floods, Perugia, Italy, Water Resources Research and Documentation Center of Colorado State University, USA, 13-17, 1995.

Catani, F., Casagli, N., Ermini, L., Righini, G., and Menduni, G.: Landslide hazard and risk mapping at catchment scale in the Arno River basin, Landslides, 2, 329-342, 2005.

Catani, F., Falorni, G., Leoni, L., and Segoni, S.: Watershedbased landslide yield assessment as a new basis for model validation, European Geosciences Union General Assembly 2008 Wien, Geophysical Research Abstracts, Vol. 10, EGU2008-A12217, 13-18 April 2008.

Catani, F., Segoni, S., and Falorni, G.: A geomorphologybased approach to the spatial prediction of soil thickness at catchment scale, Water Resour. Res., in press, doi:10.1029/2008WR007450, 2009.

Chadwick, J., Thackray, G., and Dorsch, S.: Landslide surveillance: new tools for an old problem, EOS T. Am. Geophys. Un., 86(11), doi:10.1029/2005EO110001, 2005.

Conacher, A. J. and Dalrymple, J. B.: The nine unit landsurface model: an approach to pedogeomorphic research, Geoderma, 18, $1-153,1977$.

Crosta, G. B. and Frattini, P.: Distributed modelling of shallow landslides triggered by intense rainfall, Nat. Hazards Earth Syst. Sci., 3, 81-93, 2003, http://www.nat-hazards-earth-syst-sci.net/3/81/2003/.

Cruden, D. M. and Varnes, D. J.: Landslide types and processes, in: Landslides investigation and mitigation (special report 247 (national research council, US)), edited by: Turner, A. K. and Schuster, R. L., Transportation Research Board, 673 pp., 1996.

Cuccoli, F.: Spatial rainfall rate estimation through combined use of radar reflectivity and rain-gauge data, IEEE T. Geosci. Remote, 2004. 
Delogu, F.: Data driven development of a hydrological model exploiting remotely sensed observations, Ph.D. thesis, Università degli Studi della Basilicata, 2008.

Dickinson, R. E.: The Force-Restore Model for Surface Temperatures and its Generalization, J. Climate, 1, 1086-1097, 1988.

Droegemeier, K. K., Smith, J., Businger, S., Doswell III, C., Doyle, J., Duffy, C., Foufoula-Georgiou, E., Graziano, T., James, L. D., Krajewski, V., LeMone, M., Lettenmaier, D., Mass, C., Pielke Sr., R., Ray, P., Rutledge, S., Schaake, J., and Zipser, E.: Hydrological Aspects of Weather Prediction and Flood Warnings: Report of the Ninth Prospectus Development Team of the US, Weather Research Program, B. Am. Meteorol. Soc., 81(11), 2665-2680, 2000.

Ferraris, L., Rudari, R., and Siccardi, F.: The uncertainty in the prediction of flash floods in the northern Mediterranean environment, J. Hydrometeorol., 3, 714-727, 2002.

Ferraris, L., Gabellani, S., Parodi, U., Rebora, N., von Hardenberg, J., and Provenzale, A.: Revisiting multifractality in rainfall fields, J. Hydrometeorol., 4, 544-551, 2003a.

Ferraris, L., Gabellani, S., Rebora, N., and Provenzale, A.: A comparison of stochastic models for spatial rainfall downscaling, Water Resour. Res., 39, 1368-1384, 2003b.

Gabellani, S.: The propagation of uncertainty in the rainfall-runoff models for operational flood forecasting, Ph.D. thesis, University of Genoa, Italy, 2005.

Gabellani, S., Giannoni, F., Parodi, A., Rudari, R., Taramasso, A. C., and Roth, G.: Applicability of a forecasting chain in a different morphological environment in Italy, Adv. Geosci., 2, 131134, 2005, http://www.adv-geosci.net/2/131/2005/.

Gabellani, S., Silvestro, F., Rudari, R., and Boni, G.: General calibration methodology for a combined Horton-SCS infiltration scheme in flash flood modelling, Nat. Hazards Earth Syst. Sci., 8, 1317-1327, 2008, http://www.nat-hazards-earth-syst-sci.net/8/1317/2008/.

Gabet, E. J., Burbank, D. W., Putkonen, J. K., Pratt-Sitaula, B. A., and Ojha, T.: Rainfall thresholds for landsliding in the Himalayas of Nepal, Geomorphology, 63, 131-143, 2004.

Gessler, P. E., Chadwick, O. A., Chamran, F., Althouse, L., and Holmes, K.: Modelling soil-landscape and ecosystem properties using terrain attributes, Soil Sci. Soc. Am. J., 64, 2046-2056, 2000.

Giannoni, F., Roth, G., Rudari, R., and Semi, A.: Distributed rainfall - runoff model based on a geomorphologic approach, Phys. Chem. Earth, 25/7-8, 665-671, 2000.

Giannoni, F., Roth, G., and Rudari, R.: A procedure for drainage network identification from geomorphology and its application to the prediction of the hydrologic response, Adv. Water Resour., 28(6), 567-581, 2005.

Glade, T., Crozier, M., and Smith, P.: Applying probability determination to refine landslide-triggering rainfall thresholds using an empirical 'antecedent daily rainfall model', Pure Appl. Geophys., 157, 1059-1079, 2000.

Goudenhoofdt, E. and Delobbe, L.: Evaluation of radar-gauge merging methods for quantitative precipitation estimates, Hydrol. Earth Syst. Sci., 13, 195-203, 2009, http://www.hydrol-earth-syst-sci.net/13/195/2009/.

Guillot, G. and Lebel, T.: Disaggregation of Sahelian Rainfall Fields, further developments, J. Geophys. Res., 104(D24), 31533-31553, 1999.
Guzzetti, F., Carrara, A., Cardinali, M., and Reichenbach, P.: Landslide hazard evaluation: a review of current techniques and their application in a multi-scale study, central Italy, Geomorphology, 31, 181-216, 1999.

Guzzetti, F., Peruccacci, S., Rossi, M., and Stark, C. P.: The rainfall intensity-duration control of shallow landslides and debris flows: an update, Landslides, 5, 3-17, 2008.

von Hardenberg, J., Ferraris, L., Rebora, N., and Provenzale, A.: Meteorological uncertainty and rainfall downscaling, Nonlin. Processes Geophys., 14, 193-199, 2007, http://www.nonlin-processes-geophys.net/14/193/2007/.

Heimsath, A. M., Dietrich, W. E., Nishiizumi, K., and Finkel, R. C.: Cosmogenic nuclides, topography, and the spatial variation of soil depth, Geomorphology, 27, 151-172, 1999.

Hervas, J., Barredo, J., Rosin, P., Pasuto, A., Mantovani, F., and Silvano, S.: Monitoring landslides from optical remotely sensed imagery: The case story of Tessina landslide, Italy, Geomorphology, 54, 63-75, 2003.

Hostetler, S. W.: Hydrologic and atmospheric models: The (continuing) problem of discordant scales, Climatic Change, 345-350, 2005.

Innes, J. L.: Debris flows, Prog. Phys. Geog., 7, 469-501, 10.1177/030913338300700401, 1983.

Iverson, R. M.: Landslide triggering by rain infiltration, Water Resour. Res., 36, 1897-1910, 2000.

Johnson, K. A. and Sitar, N.: Hydrologic conditions leading to debris-flow initiation, Can. Geotech. J., 27, 789-801, 1990.

Keefer, D. K., Wilson, R. C., Mark, R. K., Brabb, E. E., Brown, W. M., Ellen, S. D., Harp, E. L., Wieczorek, G. F., Alger, C. S., and Zatkin, R. S.: Real-time landslide warning during heavy rainfall, Science, 238, 921-925, 10.1126/science.238.4829.921, 1987.

Koistinen, J. and Puhakka, T.: An improved spatial gauge-radar adjustment technique, 20th conference on radar meteorology, AMS Boston, USA, 179-186, 1981.

Krajewski, F.: Cokriging radar-rainfall and rain gage data, J. Geophys. Res., 92, 9571-9580, 1987.

Larsen, M. C. and Simon, A.: A rainfall intensity-duration threshold for landslides in a humid-tropical environment, Puerto Rico, Geogr. Ann. A,, 75, 13-23, 1993.

Leoni, L., Segoni, S., Cinti, L., Falorni, G., and Catani, F.: Assessment of an infinite slope stability approach for shallow landslides: validation and sensitivity analyses, European Geosciences Union General Assembly 2008, Wien, 13-18 April 2008, Geophysical Research Abstracts, Vol. 10, EGU2008-A11056, 2008.

Leoni, L.: Shallow landslides triggered by rainfall: integration between ground-based weather radar and slope stability models in near-real time, Ph.D. thesis, Università degli Studi di Firenze, Department of Earth Sciences, Florence, Italy, 2009.

Mancini, M. and Troch, P.: Experimental Set-up for Soil Moisture Profile Determination using Multi-frequencies Back-scattering Data, EMSL Newsletter, 5, 6-8, 1995.

Metternicht, G., Hurni, L., and Gogu, R.: Remote sensing of landslides: An analysis of the potential contribution to geo-spatial systems for hazard assessment in mountainous environments, Remote Sens. Environ., 98, 284-303, 2005.

Michelson', D. B. and Koistinen, J.: Gauge-Radar Network Adjustment for the Baltic Sea Experiment, Phys. Chem. Earth Pt. B, 25(10-12), 915-920, 2000. 
Mitchell, J. and Soga, K.: Fundamentals of soil behaviour, John Wiley \& Sons Ltd., Chichester, UK, 2005.

Moore, I. D., Gessler, P. E., and Nielson, G. A.: Soil attribute prediction using terrain analysis, Soil Sci. Soc. Am. J., 57, 443-452, 1993.

Montgomery, D. R. and Dietrich, W. E.: A physically based model for the topographic control on shallow landsliding, Water Resour. Res., 30, 1153-1172, 1994.

Montgomery, D. R., Sullivan, K., and Greenberg, H. M.: Regional test of a model for shallow landsliding, Hydrol. Process., 12, 943-955, 1998.

Neitsch, S. L., Arnold, J. G., Kiniry, J. R., Williams, J. R., and King, K. W.: Soil and Water Assessment Tool Theoretical Documentation - Version 2000. TWRI Report TR-191, Texas Water Resources Institute, College Station, TX, 2002a.

Neitsch, S. L., Arnold, J. G., Kiniry, J. R., Srinivasan, R., and Williams, J. R.: Soil and Water Assessment Tool User's Manual - Version 2000. TWRI Report TR-192. Texas Water Resources Institute, College Station, TX, 2002b.

Pack, R. P., Tarboton, D. G., and Goodwin, C. N.: The Sinmap approach to terrain stability mapping, 8th Congress of the International Association of Engineering Geology, Vancouver, Canada, 1157-1165, 21-25 September 1998.

Perica, S. and Foufoula-Georgiou, E.: Model for multiscale disaggregation of spatial rainfall based on coupling meteorological and scaling descriptions, J. Geophys. Res., 101, 26347-26361, 1996.

Rebora, N., Ferraris, L., von Hardenberg, J., and Provenzale, A.: Rainfall downscaling and flood forecasting: a case study in the Mediterranean area, Nat. Hazards Earth Syst. Sci., 6, 611-619, 2006, http://www.nat-hazards-earth-syst-sci.net/6/611/2006/.

Rebora, N., Ferraris, L., von Hardenberg, J., and Provenzale, A.: RainFARM: Rainfall Downscaling by a Filtered Autoregressive Model, J. Hydrometeor., 7, 724-738, 2006.

Ren, D. and Xue, M.: A Revised Force - Restore Model for Land Surface Modelling, J. Appl. Meteorol., 43, 1768-1782, 2004.

Saco, P. M., Willgoose, G. R., Hancock, G. R.: Spatial organization of soil depths using a landform evolution model, J. Geophys. Res.-Earth, 111, F02016, doi:10.1029/2005JF000351, 2006.

Salciarini, D., Godt, J. W., Savage, W. Z., Conversini, P., Baum, R. L., and Michael, J. A.: Modelling regional initiation of rainfallinduced shallow landslides in the eastern Umbria Region of central Italy, Landslides, 3, 181-194, 2006.

Saulnier, G. M., Beven, K., and Obled, C.: Including spatially variable effective soil depths in TOPMODEL, J. Hydrol., 202(1), 158-172, 1997.

Schmidt, J., Turek, G., Clark, M. P., Uddstrom, M., and Dymond, J. R.: Probabilistic forecasting of shallow, rainfall-triggered landslides using real-time numerical weather predictions, Nat. Hazards Earth Syst. Sci., 8, 349-357, 2008, http://www.nat-hazards-earth-syst-sci.net/8/349/2008/.

Schmugge, T. J., Jackson, T. J., and McKim, H. L.: Survey of Methods for Soil Moisture Determination, Water Resour. Res., 16(6), 961-979, 1980.

Segoni, S.: Elaborazione ed applicazioni di un modello per la previsione dello spessore delle coperture superficiali, Ph.D. thesis, Università degli Studi di Firenze, Department of Earth Sciences, Florence, 2008.

Segoni, S. and Catani, F.: Modelling soil thickness to enhance slope stability analysis at catchment scale, 33rd International Geological Congress, Oslo, Norway, 6-14 August 2008.

Selby, M. J.: Hillslope materials and processes, Oxford University Press, Oxford, UK, 451 pp., 1993.

Siccardi, F.: Rainstorm hazards and related disasters in the western Mediterranean region, Remote Sens. Rev., 14, 5-21, 1996.

Siccardi, F., Boni, G., Ferraris, L., and Rudari, R.: A hydrometeorological approach for probabilistic flood forecast, J. Geophys. Res., 110, D05101, doi:10.1029/2004JD005314, 2005.

Simoni, S., Zanotti, F., Bertoldi, G., and Rigon, R.: Modelling the probability of occurrence of shallow landslides and channelized debris flows using geotop-fs, Hydrol. Process., 22, 532-545, 2008.

Singh, V. P.: Mathematical modelling of watershed hydrology, J. Hydrol. Eng., 7, 270-292, 2002.

Skempton, A. W. and Delory, F. A.: Stability of natural slopes in London clay, 4th International Conference on Soil Mechanics, 1957.

Soeters, R. and van Westen, C. J.: Slope instability recognition, analysis, and zonation, in: Landslides, investigation and mitigation, edited by: Turner, A. K. and Schuster, R. L., National Academy Press, Washington, D.C., USA, Transportation Research Board, National Research Council, Special Report, 247, 129-177, 1996.

Taylor, G. and Eggleton R. A.: Regolith geology and geomorphology, John Wiley \& Sons, Chichester, 384 pp., 2001.

Tonelli, F., Galli, G., and Borga, M.: The application of radar-gauge comparison for bias adjustment of radar observations in an alpine environment, Proceedings of ERAD, 352-356, 2002.

Van Asch, T. W. J., Buma, J., and Van Beek, L. P. H.: A view on some hydrological triggering systems in landslides, Geomorphology, 30, 25-32, 1999.

Velasco-Forero, C. A., Seed, A., and Sempere-Torres, D.: Optimal estimation of rainfall fields merging radar and rain gauges data in an operational context, ERAD, 2008.

Velasco-Forero, C. A., Sempere-Torres, D., Cassiraga, E. F., and Gómez-Hernández, J. J.: A non-parametric automatic blending methodology to estimate rainfall fields from rain gauge and radar data, Adv. Water Resour., 32, 986-1002, 2009.

Vincendon, B., Chancibault, K., Ducrocq, V., Bouilloud, L., Saulnier, G-.M., Lelay, M., Kotroni, V., Lagouvardos, K., Milelli, M., Rabuffetti, D., and Dierer, S.: Flash-flood forecasting within the PREVIEW PROJECT: value of High-resolution hydrometeorological coupled forecast, Meteorol. Atmos. Phys., 103, 115-125, doi:10.1007/s00703-008-0315-6, 2009.

Venugopal, V., Foufoula-Georgiou, E., and Sapozhnikov, V.: A space-time downscaling model for rainfall, J. Geophys. Res., 104, 19705-19721, 1999.

Wieczorek, G. F.: Effect of rainfall intensity and duration on debris flows in the central Santa Cruz mountains, California, in: Debris flows/avalanches: Process, recognition, and mitigation, edited by: Costa, J. E. and Wieczorek, G. F., Geological Society of America, Boulder, Colorado, USA, 93-104, 1987.

Wieczorek, G. F.: Landslide triggering mechanisms, National Research Council, Transportation Research Board, Special Report, 247, 76-90, 1996.

Wu, W. and Sidle, R. C.: A distributed slope stability model for steep forested basins, Water Resour. Res., 31, 2097-2110, 1995. 